\title{
Problems Faced by Married Women with Epilepsy in Indian Scenario: A Hospital-Based Study
}

\author{
Sunil Kumar Sharma ${ }^{1}$ Vijay Sardana ${ }^{1}$ Dilip Maheshwari ${ }^{1}$ Bharat Bhushan ${ }^{1}$ Nishtha Jain \\ Prashant Shringi ${ }^{1} \quad$ Rahi Kiran Bhattiprolu ${ }^{1}$
}

${ }^{1}$ Department of Neurology and Medicine, Government Medical College (GMC), Kota, Rajasthan, India

Address for correspondence Sunil Kumar Sharma, DM, Flat no. 405, Chambal Residency, Nayapura Kota, Rajasthan, India (e-mail: sks200166@rediffmail.com).

Int J Epilepsy 2018;5:80-86

\begin{abstract}
Background Epilepsy is still being considered as a social stigma especially in developing countries such as India. This study was conducted to analyze the problems faced by married women with epilepsy in various aspects of personal and social life.

Objectives The main purpose of this article is to study the psychosocial problems, drug compliance, clinical course, attitude of in-laws, and effect of epilepsy on pregnancy and its outcome in married women with epilepsy in Indian scenario.

Design, Materials, and Methods This is a prospective observational study including 100 patients. Questionnaire-based face-to-face interview of all the patients was conducted. Patients were divided into informed and concealed groups and various attributes and their significance were compared. Statistical analysis was performed using SPSS-20.0 and Microsoft Office Excel software.

Results Out of 100 patients, a total of 58 (58\%) patients had informed prior to marriage, while 42 (42\%) concealed it. Attitude of husband was negative in 33\% ( 14 out of 42 ) of concealed group and was statistically significant $(p=0.03)$. Statistically significant adverse marital outcome was observed in concealed group and Muslim community $(p=0.0001)$. Majority of the patients in both groups $(86 \%)$ opined that it

Keywords

- married women with epilepsy

- social stigma

- marital outcome should be disclosed prior to marriage.

Conclusion In a developing country such as India, epilepsy is still considered a social stigma that can manifest as felt or enacted stigma. Previous studies clearly indicate increasing awareness. Social stigma associated with epilepsy can only be eliminated with collaborative efforts of healthcare professional, government, and general public.
\end{abstract}

\section{Introduction}

The word epilepsy is derived from the Greek verb epilambanein, meaning to be seized, to be overwhelmed by surprise. People with epilepsy (PWE) are more often "seized by" difficult social environments and negative attitudes than by epileptic seizures. PWE were regarded as "being chosen" or "being possessed," depending on the prevailing popular belief; this affected treatment and society's attitudes toward PWE. Most debilitated PWE are not necessarily those who have the highest seizure rates but rather those who do not have adequate social support.

received

August 2, 2018

accepted after revision

September 29, 2018

published online

January 07, 2019
The public perception is that it is a form of madness and is incurable. It is tougher for women suffering from epilepsy to find a groom. They and their families often hide this from the husband and in-laws. Epilepsy has impacts on various aspects of social life of PWE. In India, most of the marriages are arranged by parents and their social contacts. It is very common practice to hide this condition during marital negotiation due to fear of rejection. These PWE are less likely to get married and more likely to get divorced in comparison to the general population. ${ }^{1,2}$ Many cases are left untreated; people are abused, locked up, hidden from public view, and considered mad. 
In India, sociocultural practices are more inclined toward male gender, so the women with epilepsy face more problems compared with men. Epilepsy has impacts on various aspects of social life of a woman. Some of the important issues concerned with women with epilepsy are perceived and enacted stigmas, management of epilepsy when the information is concealed from in-laws during marital negotiation, management of epilepsy during pregnancy, and its complications.

There are some international ${ }^{2-9}$ and Indian studies ${ }^{1,10-13}$ regarding the influence of stigmatization of epilepsy on marital life of women with epilepsy. We conducted this study concerning various sociocultural, psychological, and medical problems faced by married women with epilepsy in Indian scenario.

\section{Aims and Objectives}

Following are the aims and objectives of this article:

Primary objective: To study the psychosocial problems, drug compliance, clinical course, and effect of epilepsy on pregnancy and its outcome in married women with epilepsy in Indian scenario.

Secondary objective: To study the attitude of in-laws toward married women with epilepsy.

\section{Materials and Methods}

This is a prospective observational study. Hundred patients were enrolled during January 2017 to November 2017 attending Neurology outpatient department (OPD) and admitted in different wards of MBS Hospital, Kota, Rajasthan after obtaining informed consent. Approval of the Institutional Ethics Committee was taken before starting the study. Questionnaires proforma have been provided as supplementary material (-Supplementary Fig. 1, available in online version only). Patient's details were kept confidential on patient's request. Data analysis was performed by author (S.K.S) himself with the help of statistician using SPSS 20.0, Microsoft Office Excel software. We used mean, median, standard deviation, and percentages to summarize the data. The $t$-test and chi-square test were used to evaluate the statistical significance of the differentials in the survey responses. A $p$-value of $<0.05$ was considered significant.

\section{Inclusion Criteria}

- All married women with a clinical diagnosis of epilepsy (according to definitions of International league against epilepsy [ILAE]) attending Neurology OPD and admitted in different wards of MBS Hospital, Kota, Rajasthan.

\section{Exclusion Criteria}

- Patients with pseudoseizure.

- Patients having psychiatric or other neurological illnesses along with epilepsy.

- Epilepsy onset after pregnancy.

- Patients who did not want to disclose the seizure onset before marriage.

- Patients who were not willing to give consent to participate in the study.
All patients who fulfill the inclusion/exclusion criteria underwent

- History and scrutiny of previous medical records.

- Relevant clinical examination and investigations.

- Face-to-face interview based on pre-set questionnaires.

\section{Results}

A total of 100 married women with epilepsy having onset of seizure prior to marriage (PTM) were studied. Baseline and various psychosocial aspects related to the problems encountered by these patients during various stages of married life have been analyzed. The baseline demographic characteristics are highlighted in - Table $\mathbf{1}$. The patients were divided into informed and concealed groups depending on the disclosure of epilepsy PTM and various attributes were compared between these two groups. Special emphasis was given to drug compliance, drug keeping, specialist visit if not informed, marital outcome, pregnancy outcome, attitude of husband and in-laws, and advise to women with epilepsy who are planning to get married.

A total of 58 patients (58\%) had informed PTM, while 42 (42\%) concealed the history of epilepsy during marital negotiation. Among 58 women, 20 (34\%) women disclosed to husband, 1 (2\%) to in-laws, and $37(64 \%)$ to both husband and in-laws PTM ( - Fig. 1), while 42 (42\%) patients concealed the presence of epilepsy.

The decision of nondisclosure was taken by parents in $57 \%$ cases, while parents and patients decided to conceal in $43 \%$ cases. The mean age of patients was $27.1 \pm 6.53$. Mean age of epilepsy onset was $13.8 \pm 5.01$ and marriage was $19.91 \pm 2.38$. All the patients belonged to two religions:75 (75\%) Hindu and 25 (25\%) Muslims. Only 32 (32\%) patients had educational qualification of intermediate or above, while remaining patients (68\%) had educational qualification of high school or lower. There was no statistically significant difference in disclosure rates among the patients with different educational qualifications. Majority of patients were housewife in both the groups. Three patients from informed group were employed, but one of them left her job after marriage, while only one patient of the concealed group was employed.

As majority of marriages in India are being fixed by parents and other relatives, in this study also 92 (92\%) marriages were arranged, while only $8(8 \%)$ marriages were love marriages. There was statistically significant difference in the rate of disclosure between arranged and love marriages as all the patients with love marriage had informed husband or in-laws PTM, while 42 out of 92 patients with arranged marriage concealed the epilepsy $(p=0.01)$.

Majority of patients were diagnosed with idiopathic generalized epilepsy (71\%), 25\% patients had juvenile myoclonic epilepsy, and 5\% had post-traumatic epilepsy. Seizure frequency after marriage decreased in 22 (22\%), increased in 23 (23\%), and remained unchanged in remaining 55 (55\%) patients, and there was no statistically significant correlation between the two groups. Seventy-eight out of 100 patients had conceived. Seizure frequency during pregnancy 
82 Problems Faced by Married Women with Epilepsy Sharma et al.

Table 1 Demographic and clinical characteristics of 100 women with epilepsy

\begin{tabular}{|c|c|c|c|c|}
\hline \multicolumn{2}{|l|}{ Variables } & Informed & Concealed & $p$-Value \\
\hline \multicolumn{2}{|l|}{ Number of patients } & $58(58 \%)$ & $42(42 \%)$ & - \\
\hline \multicolumn{2}{|c|}{ Age of patient (years) $(27.1 \pm 6.53)$} & $26.48 \pm 6.47$ & $27.95 \pm 6.67$ & - \\
\hline \multicolumn{2}{|c|}{ Age at epilepsy onset (years) $(13.8 \pm 5.01)$} & $13.7 \pm 5.14$ & $13.92 \pm 4.88$ & - \\
\hline \multicolumn{2}{|c|}{ Age at marriage $(19.91 \pm 2.38)$} & $20.22 \pm 2.49$ & $19.47 \pm 2.16$ & NS \\
\hline \multicolumn{2}{|c|}{ Duration of marriage (years) $(7.36 \pm 5.99)$} & $6.5 \pm 5.51$ & $8.54 \pm 6.48$ & 0.16 \\
\hline \multirow[t]{2}{*}{ Religion } & Hindu (75) & 44 & 31 & \multirow[t]{2}{*}{0.95} \\
\hline & Muslim (25) & 14 & 11 & \\
\hline \multirow[t]{5}{*}{ Education } & Illiterate & 8 & 8 & \multirow[t]{5}{*}{0.17} \\
\hline & Primary & 20 & 12 & \\
\hline & High school & 8 & 12 & \\
\hline & Intermediate & 15 & 9 & \\
\hline & $\geq$ Graduation & 7 & 1 & \\
\hline \multirow[t]{3}{*}{ Occupation } & Housewife & 55 & 41 & \multirow[t]{3}{*}{0.6} \\
\hline & Employed & 2 & 1 & \\
\hline & Left job & 1 & 0 & \\
\hline \multirow[t]{2}{*}{ Type of marriage } & Arranged & 50 & 42 & \multirow[t]{2}{*}{0.01} \\
\hline & Love & 8 & 0 & \\
\hline \multirow[t]{2}{*}{ Type of living family } & Joint & 47 & 35 & \multirow[t]{2}{*}{0.76} \\
\hline & Nuclear & 11 & 7 & \\
\hline \multirow{3}{*}{$\begin{array}{l}\text { Epilepsy syndromic } \\
\text { diagnosis }\end{array}$} & Idiopathic & 38 & 33 & \multirow[t]{3}{*}{0.30} \\
\hline & JME & 17 & 7 & \\
\hline & Post-traumatic & 3 & 2 & \\
\hline \multicolumn{2}{|l|}{ Variables } & Informed 58 (58\%) & Concealed 42 (42\%) & $p$-Value \\
\hline \multirow[t]{5}{*}{ Seizure frequency } & Daily & 0 & 2 & \multirow[t]{5}{*}{0.42} \\
\hline & Weekly & 17 & 10 & \\
\hline & Monthly & 23 & 16 & \\
\hline & Half yearly & 4 & 5 & \\
\hline & Yearly & 14 & 9 & \\
\hline \multirow{3}{*}{$\begin{array}{l}\text { Frequency of seizures } \\
\text { after marriage }\end{array}$} & Decreased (22) & 15 & 7 & \multirow[t]{3}{*}{0.22} \\
\hline & Increased (23) & 10 & 13 & \\
\hline & Unchanged (55) & 33 & 22 & \\
\hline \multirow[t]{2}{*}{ Attitude of husband } & Negative & 9 & 14 & 0.036 \\
\hline & Positive & 49 & 28 & \\
\hline Attitude of in-laws & Negative & 9 & 10 & 0.29 \\
\hline & Positive & 49 & 32 & \\
\hline Marital outcome & Good & 50 & 32 & 0.19 \\
\hline & $\begin{array}{l}\text { Poor (divorce, } \\
\text { separate) }\end{array}$ & 8 & 10 & \\
\hline AED changed during & No & 38 & 31 & 0.90 \\
\hline pregnancy & Yes & 1 & 1 & \\
\hline & Stopped & 3 & 3 & \\
\hline & Not applicable & 16 & 7 & \\
\hline Variables & & Informed 58 (58\%) & Concealed 42 (42\%) & $p$-Value \\
\hline Seizure frequency & Decreased (19) & 13 & 6 & 0.059 \\
\hline during pregnancy & Increased (20) & 8 & 14 & \\
\hline & Unchanged (39) & 25 & 14 & \\
\hline
\end{tabular}


Table 1 (continued)

\begin{tabular}{|l|l|l|l|l|}
\hline \multicolumn{2}{|l|}{ Variables } & Informed & Concealed & -Value \\
\hline \multirow{2}{*}{$\begin{array}{l}\text { Adverse pregnancy } \\
\text { outcome }\end{array}$} & No & 28 & 31 & 0.02 \\
\cline { 2 - 4 } & $\begin{array}{l}\text { Yes (abortion/IUD/still } \\
\text { birth/CONG. MALF.) }\end{array}$ & 18 & 6 & 0.30 \\
\hline $\begin{array}{l}\text { Opinion of patients } \\
\text { regarding disclosure }\end{array}$ & $\begin{array}{l}\text { Disclose to husband } \\
\text { after marriage }\end{array}$ & 5 & 2 & 27 \\
\cline { 2 - 4 } & $\begin{array}{l}\text { Disclose to husband } \\
\text { and in-laws PTM }\end{array}$ & 29 & 12 & \\
\cline { 2 - 5 } & $\begin{array}{l}\text { Disclose to husband } \\
\text { PTM }\end{array}$ & 18 & 1 & \\
\cline { 2 - 5 } & Don't disclose PTM & 6 & 2 & \\
\hline
\end{tabular}

Abbreviations: Cong. Malf., congenital malformation; AED, Antiepileptic drug; IUD, intrauterine death; ME, juvenile myoclonic epilepsy; PTM, prior to marriage.

$p$-Value of $\leq 0.05$ is taken as statistically significant.

was decreased in 19 out of 78 patients (24\%), increased in $20(26 \%)$, and remained unchanged in remaining 39 (50\%) patients. The increase in seizure frequency was noted significantly higher in the concealed group as compared with the informed group. Antenatal ultrasonography was done in $82 \%$ of patients who conceived and there was no significant difference between the groups. Adverse pregnancy outcome in the form of abortions, intrauterine death (IUD), still birth, and congenital malformation were significantly higher in informed group, that is, 18 (39\%) out of 46 patients as compared with $6(16 \%)$ out of 37 patients in concealed group. The most common poor pregnancy outcomes noted were abortions followed by still birth and IUD. Neural tube defect was noted in one patient and is alive.

Attitude of husband was negative in $16 \%$ (9 out of 58 ) cases of informed group, while 33\% (14 out of 42 ) in concealed group and was statistically significant $(p=0.03)$. Attitude of in-laws was positive in majority of cases (81\%), and there was no statistically significant difference between two comparison groups. Marital outcome was more unfavorable in the concealed group as compared with informed group as 10 (24\%) out of 42 patients were either divorced or living separately compared with $8(14 \%)$ patients out of 58 in the informed group. However, the difference was not statistically significant $(p=0.19)$. On comparing marital outcome between two religions, there was statistically significant difference $(p=0.0001$ ) between Hindu and Muslim communities as 7 (9\%) out of 75 patients in the Hindu community and 11 (44\%) out of 25 patients in the Muslim community had unfavorable outcome (-Fig. 2). Divorce rate was higher in the Muslim community as all the eight divorced patients belonged to the same community. All the Hindu patients with unfavorable outcome were living separately from their spouse and none have been divorced. Ten patients were living separately from their spouse and among them three were Muslims, while seven were Hindus. There was statistically significant difference of drug compliance between the two groups $(p=0.004)$. Drug compliance was better in informed group (90\%) as compared to concealed group (33\%) (-Table 2).

Majority of patients concealed the epilepsy due to fear of anticipated breakup of marital negotiation (55\%), and $21 \%$ did not consider it to be disclosed, while $24 \%$ patients thought that it will be cured after marriage ( - Fig. 3 ). Thirteen $(41 \%)$ out of 31 patients in concealed group had disclosed their epilepsy to the obstetrician for the first time during pregnancy.

Irrespective of the informed or concealed group, majority of the patients in both groups (86\%) opined that it should be informed to both husband and in-laws (56\%) and husband only (30\%) PTM. Seven patients (7\%) had the opinion that it should be revealed to husband only after marriage, while seven patients (7\%) thought that it should not be disclosed PTM as it can lead to failure of marital negotiation ( - Fig. 4).

\section{Discussion}

The Hammurabi code, dated 1780 B.C., dictated that the person with epilepsy could not marry, or testify in court. In 400 B.C., Hippocrates wrote, epilepsy is no more divine than other diseases; "Its cause lies in the brain, the releasing factors of the seizures are cold, sun and winds which change the consistency of the brain. Therefore, epilepsy can and must be treated not by magic, but by diet and drugs." ${ }^{14}$ In the 15th century a professor wrote: "Therefore, neither talk nor bathe with him, since by their mere breath they infect people." ${ }^{14}$ In the 18 th century, epilepsy was still believed to be infectious. ${ }^{3}$

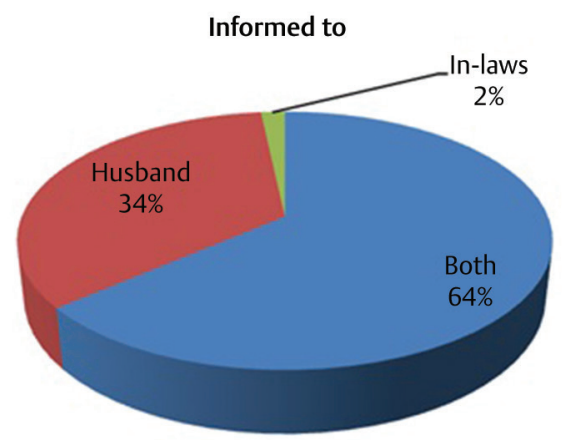

Fig. 1 Pie chart showing percentage distribution of disclosure prior to marriage. 
84 Problems Faced by Married Women with Epilepsy Sharma et al.

Table 2 Cross tabulation of drug compliance in informed and concealed groups

\begin{tabular}{|l|l|l|l|l|}
\hline \multirow{2}{*}{$\begin{array}{l}\text { Drug } \\
\text { compliance }\end{array}$} & Disclosure PTM & Grand total & p-Value \\
\cline { 2 - 5 } & Informed & Concealed & $80(80 \%)$ & 0.0046 \\
\hline Good & $52(90 \%)$ & $28(67 \%)$ & $20(20 \%)$ & 0.0046 \\
\hline Grand total & $6(10 \%)$ & $14(33 \%)$ & $100(100 \%)$ & \\
\hline
\end{tabular}

Abbreviation: PTM, prior to marriage.

$p-$ Value $=0.0046$.

$p$-Value of $\leq 0.05$ is taken as statistically significant.

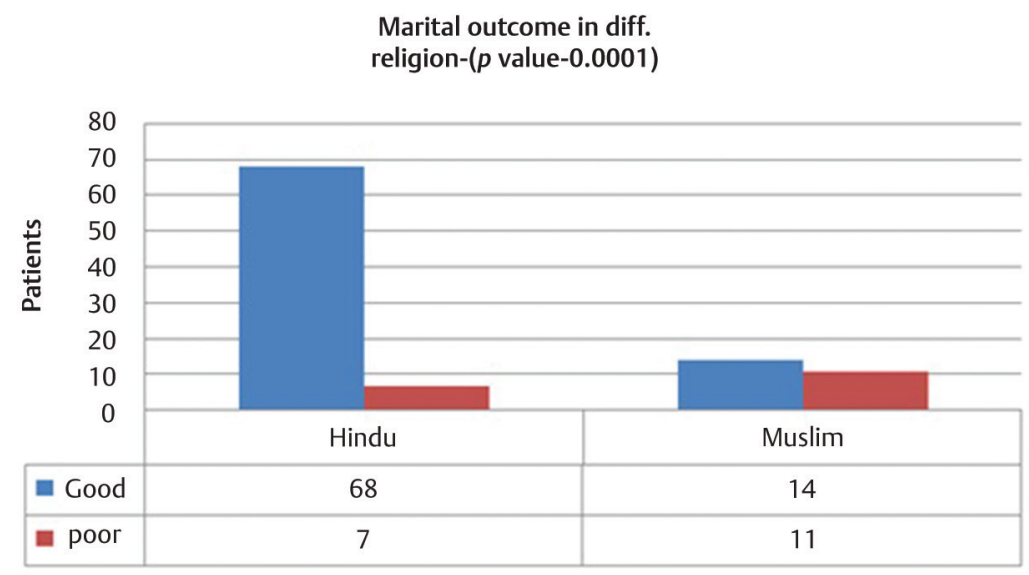

Fig. 2 Bar diagram showing marital outcome in different religions.

\section{Reasons Of Nondisclosure Of seizure $(n=42)$}

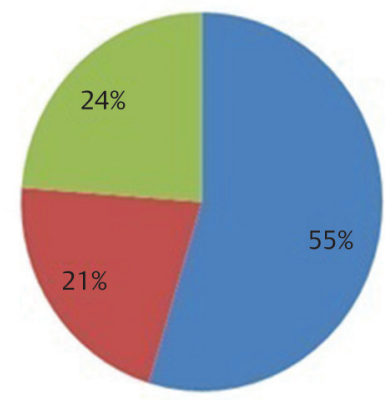

anticipated break up

Need not to be disclose

Will be cured after marriage

Fig. 3 Pie chart depicting reasons for nondisclosure of seizure.

Despite the significant clinical and therapeutic progress of the last century, PWE continue to suffer discrimination not only in the developing world but also in the developed countries. Until the 1970s, for instance, it was still legal in the United States to deny persons with seizures entry to restaurants, theaters, recreational centers, and other public places. These employment and legal restrictions further perpetuated the stigma attached to epilepsy in the modern society. ${ }^{4}$ In the United States, PWE were forbidden to marry in 17 states, until 1956. The last state to repeal this law did so only in 1980. In 1956, 18 states provided for the sterilization, on eugenic grounds, of PWE. ${ }^{15}$ In the United Kingdom, a law prohibiting PWE from marrying was repealed in 1970. The Hindu Marriage Act of 1955 and the Special Marriage Act of 
1954 stated that a marriage under these acts can be solemnized "if at the time of marriage neither party suffers from recurrent attacks of insanity or epilepsy." It took a struggle of 12 years for the Indian Epilepsy Association to have the word "epilepsy" deleted from this law. This was achieved in December $1999 .{ }^{16}$ Recently conducted knowledge, attitude, and practice (KAP) studies from developed countries have shown an emergence of a positive attitude toward epilepsy. ${ }^{5-9}$ However, epilepsy still continues to be a highly stigmatizing disease in most developing countries. ${ }^{10}$

In India, majority of marriages are being arranged by parents or relatives. Epilepsy is still considered as a social stigma and poses great difficulty for parents and women during marital negotiation. There is always a dilemma regarding disclosure of epilepsy PTM. The problem is not only limited to marital negotiation but also in other aspects of married life such as pregnancy and its outcome. The problem is more bothersome for females as social norms are more inclined toward the male gender in India.

In this study, $58 \%$ women revealed and $42 \%$ concealed the epilepsy. The study performed by Agarwal et al $^{1}$ on 240 patients with epilepsy showed that around 95.5\% patients concealed the epilepsy PTM. The study performed by Santosh et $\mathrm{al}^{11}$ at the SCTIMS Kerala with 82 women with epilepsy PTM showed that $55 \%$ of the patients concealed the history of epilepsy. In present study, more percentage of women revealed epilepsy compared with previous studies. This could be due to increasing awareness about epilepsy, increasing literacy rate, and may be due to increasing social acceptability of the illness. The main reason behind nondisclosure is fear of failure of marital negotiations in all studies.

A study by Santosh et $\mathrm{a}^{11}$ revealed that significantly higher proportion of women, who concealed, were legally divorced (18\%) or living separately from their spouses $(20 \%)$. In the present study, adverse marital outcome was reported in $18 \%$ of women with epilepsy (divorce: $8 \%$, living separately: $10 \%$ ). Adverse marital outcome was $24 \%$ in the concealed group as compared with $14 \%$ in the revealed group. Overall divorce rate of $8 \%$ was significantly higher as compared with general population in India (1.1\%). ${ }^{17}$ High divorce rate can be explained by the social stigma associated with this medical condition. Higher divorce rate in the Muslim community may be due to ease of getting divorce as compared with Hindu community. All the Hindu women with epilepsy were living separately.

Type of marriage has significant correlation with disclosure: the correlation was $100 \%$ among women who did love marriage as compared with those having arranged marriage where it was only $54 \%$ although the difference of marital outcome was not statistically significant $(p=0.16)$ between love and arranged marriages. Legal statute of divorce when one partner is having epilepsy varies from country to country. In India, epilepsy was considered as a ground for divorce along with insanity before 1999 but not so now. ${ }^{16}$ The legal consequences of nondisclosure PTM are still debatable. In a KAP study performed by Krishnaiah et al in a village of Tamil Nadu in 2016 revealed that negative attitudes appeared to be due to beliefs that epilepsy is hereditary (23.1\%), kind of insanity (22.6\%), or contagious (12.0\%). ${ }^{12}$
Attitude of husband was significantly negative in the concealed group as compared with informed group. The husband is main caregiver in majority of the Indian families; hence, his negative attitude leads to poor quality of life, poor care, and adverse marital outcome. The attitude of in-laws was not significantly different between informed and concealed groups.

Singh et $\mathrm{al}^{13}$ in their expert group appraisal found that PWE who concealed their illness during marital negotiations either discontinued their epilepsy medications or continued to take the medications covertly, which led to poor compliance and breakthrough seizures. Visits to healthcare providers also become difficult and less frequent at times (post-marriage, pregnancy, and post-pregnancy) when a specialist's advice is much required. Hiding might also be associated with increased anxiety, felt and enacted stigma. Finally, failing to disclose epilepsy might impact marital outcome. ${ }^{17}$ In majority of the patients, antiepileptics were not changed during pregnancy mainly due to improper family planning and irregular specialist visit. Among the concealed group, $21(50 \%)$ patients were having irregular specialist visit, while $6(14 \%)$ patients stopped the treatment. The concealed group had a significantly higher proportion of women with increased seizure frequency during pregnancy, which may be attributed to poor drug compliance and irregular visit to the specialist. Adverse pregnancy outcome was reported significantly high in the informed group and may be attributed to good drug compliance but irregular specialist follow-up. Most of the pregnancies were unplanned and patients had already taken antiepileptic drugs, known to have adverse pregnancy outcome, during the first trimester of pregnancy.

Irrespective of the group, $86 \%$ women opined that epilepsy should be disclosed either to husband (30\%) or both to husband and in-laws (56\%) PTM, while 7\% told to reveal to husband after marriage. The remaining $7 \%$ women were in favor of not disclosing it at all ( - Fig. 4). This observation signifies that majority of women are not willing to hide the epilepsy PTM so that future adverse circumstances can be avoided. Early counseling of the parents and women with epilepsy are of prime importance especially regarding education, self-dependence, and employment of the women with epilepsy. Social stigma related to epilepsy can only be removed with education and awareness of general public. The goal cannot be achieved unless government and some popular public figure come forward to initiate an awareness campaign in this regard with the extensive use of various means of communication (e.g., television, radio, internet, social media, print media, etc.).

The most important role the society can play for women with epilepsy is to give good social support so that the felt and enacted stigma can be removed.

\section{Conclusion}

In a developing country such as India, epilepsy is still considered a social stigma that can manifest as felt or enacted stigma. In the present study, we have studied various aspects related to the problems faced by married women with epilepsy and 


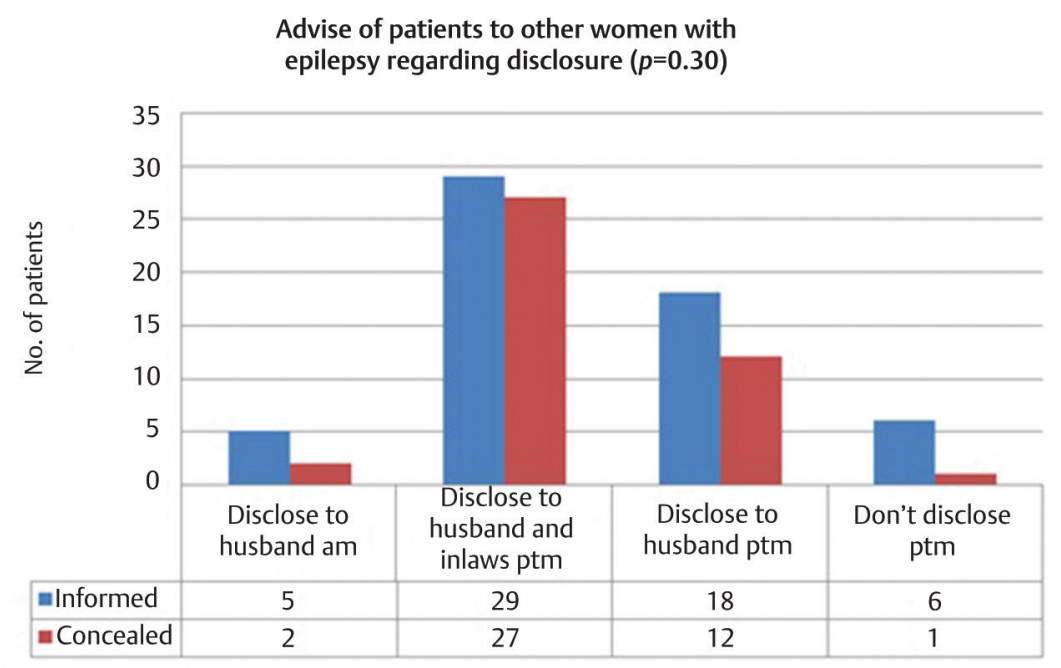

Fig. 4 Bar diagram depicting advice of patients to other women with epilepsy regarding disclosure of epilepsy.

found a significant percentage of families who are still hiding the epilepsy during marital negotiation. Social customs are more inclined toward the male gender in India. Women with epilepsy encounter a lot of psychosocial issues during marital negotiation and later part of the married life such as balancing the family life, conception, and pregnancy. Women with epilepsy have more chances of poor drug compliance, adverse pregnancy, and marital outcome as compared with general population. We also noticed significant difference between drug compliance, adverse pregnancy outcome, and unfavorable marital outcome as compared with general population. There are many international and Indian studies regarding problems related to women with epilepsy. These studies clearly indicate increasing awareness in general population regarding this issue, but still there is very long way to go and this can only be achieved with collaborative efforts of healthcare professional, government, and general public. Parents of epileptic females should be encouraged to reveal/inform about epilepsy before marriage to reduce unfavorable outcome.

\section{Funding}

None.

\section{Conflict of Interest}

None declared.

\section{Acknowledgment}

We are thankful to the Department of Medicine and Obstetrics and Gynaecology, GMC Kota, Rajasthan for their support.

\section{References}

1 Agarwal P, Mehndiratta MM, Antony AR, et al. Epilepsy in India: nuptiality behaviour and fertility. Seizure 2006;15(6):409-415

2 Wada K, Kawata Y, Murakami T, et al. Sociomedical aspects of epileptic patients: their employment and marital status. Psychiatry Clin Neurosci 2001;55(2):141-146
3 de Boer HM. Epilepsy and society. Epilepsia 1995;36(Suppl 1) :S8-S11

4 McLin WM, de Boer HM. Public perceptions about epilepsy. Epilepsia 1995;36(10):957-959

5 Caveness WF, Gallup GH Jr. A survey of public attitudes toward epilepsy in 1979 with an indication of trends over the past thirty years. Epilepsia 1980;21(5):509-518

6 Canger R, Cornaggia C. Public attitudes toward epilepsy in Italy: results of a survey and comparison with U.S.A. and West German data. Epilepsia 1985;26(3):221-226

7 Jensen R, Dam M. Public attitudes toward epilepsy in Denmark. Epilepsia 1992;33(3):459-463

8 Lai CW, Huang XS, Lai YHC, Zhang ZQ, Liu GJ, Yang MZ. Survey of public awareness, understanding, and attitudes toward epilepsy in Henan province, China. Epilepsia 1990;31(2):182-187

9 Rwiza HT, Matuja WB, Kilonzo GP, et al. Knowledge, attitude, and practice toward epilepsy among rural Tanzanian residents. Epilepsia 1993;34(6):1017-1023

10 Gambhir SK, Kumar V, Singhi PD, Goel RC. Public awareness, understanding \& attitudes toward epilepsy. Indian J Med Res 1995;102:34-38

11 Santosh D, Kumar TS, Sarma PS, Radhakrishnan K. Women with onset of epilepsy prior to marriage: disclose or conceal? Epilepsia 2007;48(5):1007-1010

12 Krishnaiah B, Alwar SP, Ranganathan LN. Knowledge, attitude, and practice of people toward epilepsy in a South Indian village. J Neurosci Rural Pract 2016;7(3):374-380

13 Singh G, Pauranik A, Menon B, et al. The dilemma of arranged marriages in people with epilepsy. An expert group appraisal. Epilepsy Behav 2016;61:242-247

14 Temkin O. The Falling Sickness. Baltimore: The Johns Hopkins University Press; 1945

15 Landover MD. The Legal Rights of Persons with Epilepsy. An Overview of Legal Issues and Laws Affecting Persons with Epilepsy, 6th ed. Epilepsy Foundation of America, United States; 1992

16 Desai K. Indian Law of Marriage and Divorce. Nagpur, India: Wadhwa and Company; 2004

17 Varma S. India In Motion - Marriages Last the Longest in N India, Maha; least in NE: The Times of India: Article Date: $01 / 18 / 2016$ 